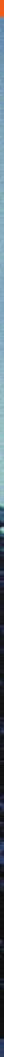

\title{
Von Luft, Licht und Sonne - und dem Recht auf dunkle Nächte
}

Enrico Danieli

Korrespondenz:

Dr. med. Enrico Danieli

Via ai Colli 22

$\mathrm{CH}-6648$ Minusio
Open airs sind aus unseren Kulturen nicht mehr wegzudenken: Unter freiem Himmel sein löst nach wie vor einen Taumel an Lebenslust aus: Freiluftkino, Freiluftkulturen - als ob es nichts Schöneres gäbe, um unsere Verliesse zu verlassen als den Gang zum unverstellten Himmel. Der Himmel als Idee einer überirdischen Vollkommenheit wie in früheren Zeiten kommt allerdings in den heutigen (klimatologisch-satellitengestützten) Zustandsberichten nicht mehr vor: Die reine Himmelsheiterkeit will keine Seele mehr erfreuen.

Wer erinnert sich noch an die Klimakuren, die Genesenden zur weiteren Rehabilitation in sogenannten Klimastationen oder Luftkurorten nachhaltig empfohlen wurden? Und wer hat nicht schon von Luftveränderung geträumt, die Ruhe in unsere von Unruhe geplagten Herzen bringen könnte? Es sind über hundert Jahre vergangen, seit die atmosphärischen Kuren entdeckt wurden und als Sonnen-, Licht- und Luftbäder in
Mode kamen. Kein Mensch, wurde damals argumentiert, kann, auch wenn der Arzt noch so begabt ist, Kranke heilen, denn nur die Natur (die Luft, die Sonne, das Klima) heilt. Ein Satz, der seine Berechtigung hat, denn alles, so scheint es, ist noch heilsame Natur, was nicht schon zerstörtes Klima ist.

$\mathrm{Zu}$ erinnern ist an die Anfänge der sogenannten Lichtluftbewegung. Auf dem Monte Verità wurden Kuren in Lufthütten empfohlen, Aufenthalte in Glassonnenhallen, in Lichtluftparks; Sommerschulen (für Bewegungstherapien) und ähnliche kreative Labors wurden auf dem Berg der Wahrheit abgehalten. Pate der Lichtlufttherapien war «Sonnendoktor» Arnold Rickli: Über den Holzliegen im Lichtluftbad sind seine Schilder zur genauen Anleitung zum Sonnenbad angebracht: Die maximale Liegezeit dauert von 3 Minuten zu Beginn bis 20 Minuten maximal. Danach hatte der erhitzte Körper im kalten Wannenbad abgekühlt oder unter der Freilicht- 
dusche entstaut zu werden. Der Schweizer Arzt war es auch, der als erster Erkrankungen mit Sonnenlicht (als «cure atmosphérique» bezeichnet) therapierte, zuerst in der Sonnenklinik Veldes in der Oberkrain, später im Naturheilsanatorium an der Adria.

Den 1903 dem norwegischen Anatomieprofessor Niels Finsen zugesprochenen Nobelpreis erhielt dieser in Anerkennung für seine erstmalig ausgeführten künstlichen Sonnenlichttherapien (gegen Lupus vulgaris, tuberkulöse Hauterkrankungen). Es ist, nüchtern betrachtet, ein Kult um Licht und Sonne, der in der Folge in den Jahren vor dem ersten Krieg Europa heimsucht und den sehnsüchtig erwarteten neuen Menschen erschafft: das lichtgeborene Lichtwesen. Differenzierungen erfolgten durch die Erfindung der Kohlenbogenlampen als Ersatzsonnen (Ove Strandberg). Möglicherweise ist es kein Zufall, dass die Lichteuphorie im Norden Europas ihren

\section{Kein Mensch, wurde damals argumentiert, kann, auch wenn der Arzt noch so begabt ist, Kranke heilen, denn nur die Natur (die Luft, die Sonne, das Klima) heilt}

Anfang nahm: Skandinavien hat das günstigste Klima für saisonal ausgelöste Depression. Anzufügen bleibt, dass insbesondere die Vitamin-DMangelerkrankung auf Lichtexposition einen der positivsten therapeutischen Effekte aufwies und aufweist. Einzuflechten sind historische Gegebenheiten: Zur wilhelminischen Zeit waren strikte Kleiderordnungen unabdingbar, Nacktheit Irrsinn. Ärzte waren es, die Kränkelnden mehr Licht verordneten: Der Kleiderdrill wurde stetig gelöst. Isadora Duncan tanzte Freiheit vor, forderte Nacktheit als Zukunftskostüm. Heinrich Pudor propagierte nacktes Baden. Und des entsetzlichen Korsettzwangs entledigten sich die Frauen mit dramatischen Kämpfen. Doch fundamental erfolgten die Umwälzungen erst im Krieg. Der Wandel der Kleidersitten ist revolutionär, revolutionärer als manche Revolution. Braucht hinzugefügt zu werden, dass - gleich der Kunst - in reaktionären Kreisen die neu errungenen Körperfreiheiten als Entartung nicht nur disqualifiziert, sondern auch verfolgt wurden? Freiheitlich orientierte FK-Kulturen konkurrenzierten mit rechtsnationalen Bünden für Leibeszucht; bis 1942 schliesslich auch die Nazis Gefallen fanden an gesunder, männlicher, nackter arischer Auslese, im Jargon natürliche Zuchtwahl geheissen.

Wie dem auch sei: In einem alten Hausarztbuch finden sich Sonne und frische Luft als Grundsäulen der Gesundheit: «Verwehre Sonne und Licht den Eintritt in Dein Hause nicht!» Doch ob das Licht nicht auch zu viel an Schaden bewirkt? Der Schwarze Krebs - ursprünglich an der über 12 Stunden pro Tag der Sonne ausgesetzten Haut der Weinbergbauern in Bordeaux beschrieben - soll heute, als Folge des Sonnenlichts, für weltweit mehr Krebserkrankungen verantwortlich sein als jeder andere karzinogene Faktor! Wohl gilt immer Paracelsus' Wort, dass auf die Dosis ankomme, was zum Gifte werde. $\mathrm{Zu}$ viel an Schaden: Als wäre es mit der Luftverschmutzung nicht genug, ist vermehrt die Rede von Lichtverschmutzung. Ein kühnes Wort: Denn es findet eine Verschmutzung nicht des Reinen, sondern durch das Reine statt. Dabei werden neben erdgestützten Lichtquellen auch Dispersionen von Licht in den Weltraum anvisiert: astrokommerzielle Verschmutzung.

So, des (verunreinigenden) Lichts, der (schädigenden) Sonne und der (verschmutzten) Luft satt, klagen wir ein Menschenrecht ein nicht nur auf saubere Luft, sauberes Licht, sondern auch auf intakte Natur und dunkle Nacht. Die Natur hat, so lernen wir, aufgehört, etwas Gleichgültiges zu sein. Wer sich schont, schont die Natur und umgekehrt. Mit dem Wandel des Klimas, als Summe aller Veränderungen der Atmosphäre verstanden, und in Erinnerung daran, dass es ursprünglich unser eigentliches (Lebens-)Element war, verändert sich das Verhältnis zu uns und zur Welt: Wir sind am Abschluss einer Entwicklung angekommen, die ganz zu Beginn und noch bis zu den Höhenflügen von Luft, Licht und Sonne von einem sinn- und kulturstiftenden Klimabegriff getragen wurde: Das Klima hat endgültig aufgehört verborgene Dimension unserer Existenz zu sein. 